\title{
Concordant oral-genital HPV infection in South Africa couples: evidence for transmission
}

\author{
${ }^{1}$ Department of Internal Medicine, University of Pittsburgh Medical Center, Pittsburgh, PA, USA \\ ${ }^{2}$ Department of Epidemiology, Johns Hopkins School of Public Health, Baltimore, MD, USA \\ ${ }^{3}$ Perinatal HIV Research Unit, University of Witwatersrand, Johannesburg, South Africa \\ 4 Johns Hopkins University School of Medicine, Baltimore, MD, USA
}

Samantha L. Vogt ${ }^{1}$, Patti E. Gravitt ${ }^{2}$, Neil A. Martinson ${ }^{3,4}$, Jennifer Hoffmann ${ }^{4}$ and Gypsyamber D'Souza ${ }^{2}$ *

\section{Edited by:}

Silvia de Sanjosé, Catalan Institute of

Oncology, Spain

Reviewed by:

Clement Adebamowo, University of Maryland Baltimore, USA

Elisabeth Couto, Norwegian

Knowledge Centre for the Health

Services, Norway

*Correspondence:

Gypsyamber D'Souza, Department of Epidemiology, Johns Hopkins School of Public Health, 615 N Wolfe Street, E6132B, Baltimore, MD 21205, USA e-mail:gdsouza@jhsph.edu
Objective: Cervical cancer is a leading cause of cancer mortality in South Africa. However, little is known about oral human papillomavirus (HPV) infection in high human immunodeficiency virus (HIV) seroprevalence settings.

Method: Thirty-four adult heterosexual couples attending an HIV testing center in Soweto, South Africa were enrolled. Each participant provided an oral rinse sample and genital swab, which were tested for 37 types of HPV DNA, and completed a risk behavior survey.

Results: Median age was 31 years and 9\% (3/34) of men and 29\% (10/34) of women enrolled tested HIV-positive; median CD 4 count was 437 cells $/ \mathrm{mm}^{3}$. Oral HPV prevalence was similar in women and men (12 vs. $18 \%, p=0.48$ ), and was non-significantly higher in HIV-infected vs. HIV-uninfected (23 vs. $13 \%, p=0.34$ ) subjects. Most men $(82 \%)$ and women $(84 \%)$ reported ever performing oral sex. Median number of lifetime sexual partners was " $2-5$ " while median number of lifetime oral sex partners was 1 . Oncogenic HPV subtypes were detected in $4 \%$ of oral, $26 \%$ of penile, and $74 \%$ of vaginal samples, including HPV16 in 1, 12, and $21 \%$ of these samples respectively. Genital HPV prevalence was significantly higher than oral HPV prevalence (75 vs. $15 \%, p \leq 0.001)$. Thirty-five percent of couples (12/34) had at least one type-specific concordant vaginal-penile HPV infection but only one of nine couples with oral HPV had concordant oral-oral infection. However, $67 \%$ (4/6) of men and $25 \%(1 / 4)$ of women with oral HPV infection had partners with concordant genital HPV infection.

Implications and Impact: Oral-oral HPV concordance between couples is low, but oralgenital and genital-genital HPV concordance is higher, including concordance of male oral HPV infection with their partners' vaginal HPV infection. This data is consistent with possible transmission of vaginal HPV infection to the oral cavity of sexual partners performing oral sex.

Keywords: HIV, oral sex, South Africa, HPV, oral, genital, concordance, transmission

\section{INTRODUCTION}

Human papillomavirus (HPV) is a sexually transmitted infection that causes squamous cervical cancer and some vaginal and anal cancers $(1,2)$. More recent data shows that HPV also causes a subset of head and neck cancers including $50-75 \%$ of oropharyngeal cancers (3). While initial cross-sectional studies from the United States suggest that oral HPV prevalence is elevated among human immunodeficiency virus (HIV)-infected individuals and further increased with immunosuppression $(4,5)$, there is currently limited information about oral HPV infections in Africa. Yet the incidence of oral cancer in South Africa is 2.7 per 100,000 per year and the incidence of pharyngeal cancer is 2.4 per 100,000 per year (6).

In South Africa, HIV prevalence is estimated at $17.3 \%$, and 5.6 million people are living with HIV as of 2011 (7). Since the advent of effective antiretroviral therapy (ART) and its roll-out in Sub-Saharan Africa, HIV-infected patients are living longer. With this increase in survival comes an increased opportunity for progression of oncogenic viral infections into malignancies, including increased incidence of HPV-associated oral, genital, and anal cancers $(8,9)$.

Cervical HPV infection has been well studied in South Africa, where cervical cancer is one of the leading causes of cancer mortality in women (10). The prevalence of cervical HPV infection approaches $80 \%$ among HIV-infected women (11) in whom high rates of cervical premalignant lesions have been reported (12), an effect apparently mitigated by ART (13). Owing to limited data on oral HPV, the concordance of oral-cervical HPV infection has not been well studied. Previous cross-sectional data from the U.S. suggests that the risk factors such as tobacco use, immunosuppression, and increasing age might also be risk factors for persistent oral HPV infection $(5,14)$. 
We therefore evaluated oral and genital HPV prevalence, risk factors and concordance among couples attending the Perinatal HIV Research Unit at Chris Baragwanath Hospital in Johannesburg, South Africa.

\section{MATERIALS AND METHODS STUDY POPULATION}

In 2011 we recruited 38 couples attending the Zazi Center at the Perinatal HIV Research Unit, Chris Baragwanath Hospital in Soweto, South Africa for HIV testing. The Zazi Center provides free, walk-in, voluntary HIV counseling and testing for individuals and couples. Clients who test positive for HIV receive CD4 count testing to assist in appropriate referral to care. To be included in this study, participants were required to be 18 years or older and be able to read English. A convenience sample that included all couples coming to the Zazi HIV testing clinic during the enrollment period were asked by their HIV testing counselor if they were interested in participating in the study. Roughly $33 \%$ of the individuals who came to the HIV clinic during this time period came without a partner and were therefore not eligible for this study. Sexually active couples who reported being together for at least 1 month were eligible for enrollment as long as both partners were willing to participate and provide informed consent. All 38 couples referred to the study coordinator enrolled in the study.

A couple was defined as two individuals (regardless of gender) who self-identified as current sexual partners. Exclusion criteria included an inability to provide consent, or an unwillingness to provide an oral rinse sample and survey data. Individuals could opt out of providing a genital sample. The study was approved by the Johns Hopkins Bloomberg School of Public Health institutional review board and the University of Witwatersrand human research ethics committee.

Each study subject provided an oral rinse and gargle sample, a genital swab and completed a risk behavior survey. Oral rinse and gargle specimens were obtained by having a participant gargle $10 \mathrm{ml}$ of Scope mouthwash for a total of $30 \mathrm{~s}(10 \mathrm{~s}$ rinse, $5 \mathrm{~s}$ gargle, $10 \mathrm{~s}$ rinse, $5 \mathrm{~s}$ gargle). Specimens were collected in a sterile cup and stored at $4^{\circ} \mathrm{C}$ while awaiting transport to the laboratory. Women were asked to provide a self-collected vaginal sample, obtained using a Dacron applicator (Qiagen female swab specimen collection kit) and stored at room temperature while awaiting transport to the laboratory. The penile swab was collected from participating men by a clinical study team member and penile cells were collected using two Dacron HC (Qiagen) swabs. One swab sampled the coronal sulcus and glans penis, while the other sampled the penile shaft. Both were combined into one collection vial and stored at room temperature (15). Initial processing was performed in South Africa including centrifugation at $2000 \mathrm{rpm}$ at $4^{\circ} \mathrm{C}$ for $10 \mathrm{~min}, 2 \mathrm{ml}$ supernatant saved, followed by re-suspension of the pellet in $10 \mathrm{ml}$ PBS and centrifuged at $2000 \mathrm{rpm}$ at $4^{\circ} \mathrm{C}$ for $10 \mathrm{~min}$ and pellet re-suspended in $3 \mathrm{ml} \mathrm{PBS}$ and split into two aliquots. All samples were stored locally at $-80^{\circ} \mathrm{C}$ until shipment to Baltimore lab for DNA purification, amplification and HPV DNA detected by line blot hybridization, as previously described $(16,17)$. Samples were tested for 37 types of HPV DNA; oncogenic HPV subtypes were defined as 16/18/31/33/35/39/45/51/52/56/58/59/68/73/82 (18-20).
All study participants were asked to complete a selfadministered risk factor questionnaire. Individuals from the same couple were asked to fill out the survey in separate rooms to ensure privacy of responses. The questionnaire included questions about risk factors for oral HPV infection including demographics, recent, and lifetime sexual behavior including performing oral sex, alcohol, tobacco, and drug use. Ever regular tobacco use was asked as: "Have you ever smoked cigarettes regularly?" with response options of: yes/no. Ever regular alcohol use was asked similarly. Responses to many of the survey questions were categorical, such as number of oral sexual partners, which was asked as: "In your lifetime, how many different people have you performed oral sex on?" with response options of: $0,1,2-5,6-10,>10$.

All study participants were tested for HIV as part of their clinical care and if HIV-positive CD4 cell count by the Zazi clinic as part of their clinical visit. Women with oncogenic vaginal HPV infection were referred for Pap smears.

\section{STATISTICAL ANALYSIS}

Characteristics of participants were compared by gender and by HIV status using chi-squared for categorical and test of medians for continuous variables. Chi-squared was used to compare oral and genital HPV prevalence by HIV-status. Fischers exact test was used is comparisons of any group with five or fewer subjects. McNemar's test was used to compare oral and genital HPV prevalence among the paired male and female couples. Agreement in HPV infections between partners was considered separately by site (oral-oral, genital-oral, and genital-genital) and was described as the proportion of couples who had one or more type-specific concordant infections overall and when limited to subgroups who had one type of infection present. All statistical analyses were performed using STATA version 11.0 (College Station, TX, USA). There were 4/38 couples recruited in which one of the partners opted out of providing a genital sample; therefore all analyses were restricted to the 34 couples with complete oral and genital HPV data. Results were similar when these individuals were not excluded (results not shown).

\section{RESULTS}

This pilot study included 13 individuals who tested positive for $\mathrm{HIV}$ infection, as well as 55 people testing HIV-negative, called HIV-uninfected (Table 1). HIV concordance was seen in 2 couples, 9 couples were HIV discordant, and 23 couples were HIVuninfected. The median CD4 count among HIV-positive individuals was 437 cells $/ \mathrm{mm}^{3}$ [Interquartile range (IQR): 161-575 cells $\left./ \mathrm{mm}^{3}\right]$. Median age was 31 years (IQR: $28-36$ ). Women were more likely than men to test HIV positive ( 29 vs. $9 \%, p=0.03$ ) and women were significantly younger and less likely to use tobacco or alcohol than men in the study (Table 1). Most men 27/33 $(82 \%)$ and women $26 / 31(84 \%)$ reported ever performing oral sex. Median number of lifetime sexual partners was 2-5 (IQR: 2$5,6-10)$, while median number of lifetime oral sex partners was 1 (IQR: 1, 2-5).

\section{HPV PREVALENCE}

There were a total of 35 different genital HPV types detected amongst the study participants, including HPV 16 and 62 (prevalence each $16.2 \%), 45$ and 52 (each 11.8\%), 61 (10.3\%), 66 (8.8\%), 
Table 1 | Characteristics of 34 couples attending Zazi Clinic for HIV counseling and testing, stratified by gender.

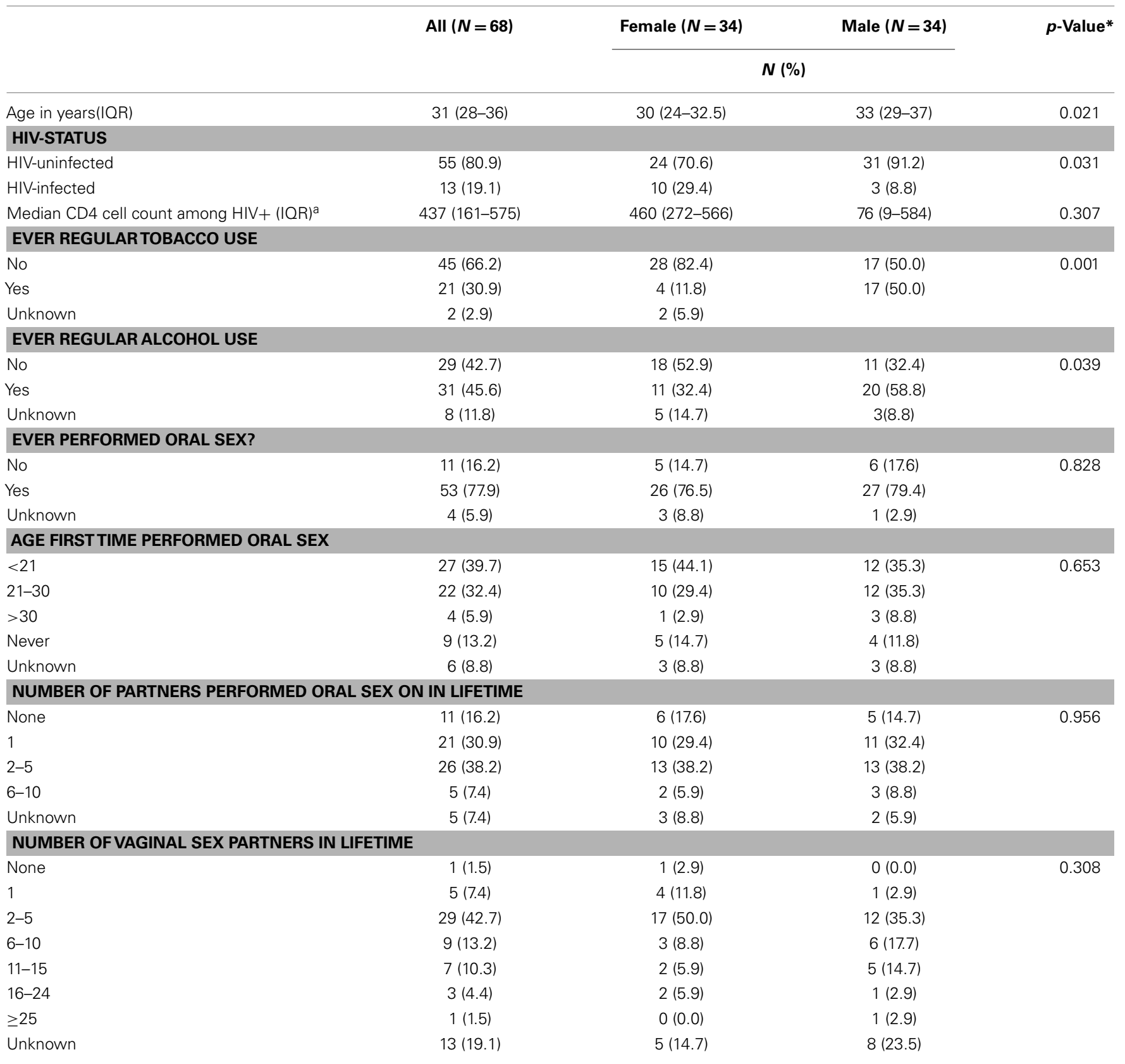

*p Values were calculated using the Mann-Whitney test for continuous variables and chi-squared for all remaining variables and excluded those with unknown values. ${ }^{a}$ CD4 cell counts were available for only 11 of the HIV-infected individuals; this included 8 females and 3 males.

$6,18,35,72,84,89$ (each $7.4 \%$ ) as the most common types. For oral HPV the most common infections detected were HPV 62 (prevalence 7.4\%), 72 (5.9\%), 35, 52, 33, 58 (each 2.9\%), and 16, 74, 66 (each 1.5\%).

Oral HPV prevalence was significantly lower than genital HPV prevalence ( 15 vs. $75 \%, p \leq 0.001$ ) (Table 2 ) but oral HPV prevalence was similar in women and men ( 12 vs. $18 \%, p=0.48)$, and was higher, but not statistically different, among HIV-infected vs. HIV-uninfected individuals (23 vs.13\%, $p=0.34$ ). Genital HPV prevalence was significantly higher in women vs. men
(91 vs. $59 \%, p=0.005$ ) and HIV-infected vs. HIV-uninfected (100 vs. $69 \%, p=0.02$ ). Oncogenic HPV subtypes were detected in $4 \%$ of oral, $29 \%$ of penile, and $74 \%$ of cervical samples, including HPV 16 in 1, 12, and $21 \%$ of these samples respectively.

Comparing HIV-infected vs. HIV-uninfected individuals, HIVinfected individuals displayed a statistically significantly higher prevalence of both genital oncogenic HPV subtypes (76.9 vs. $45.5 \%, p=0.04$ ) and multiple HPV infections ( 84.6 vs. $29.1 \%$, $p \leq 0.0001)$. For oral samples, there was a trend for higher 


\begin{tabular}{|c|c|c|c|c|c|c|}
\hline & \multicolumn{6}{|c|}{$N(\%)$} \\
\hline & $\begin{array}{l}\text { Female } \\
(N=34)\end{array}$ & $\begin{array}{l}\text { Male } \\
(N=34)\end{array}$ & $p$-Value* & $\begin{array}{l}\text { HIV-infected } \\
(N=13)\end{array}$ & $\begin{array}{l}\text { HIV-uninfected } \\
(N=55)\end{array}$ & $p$-Value ** \\
\hline \multicolumn{7}{|l|}{ ORAL HPV } \\
\hline Any & $4(11.8)$ & $6(17.7)$ & 0.48 & $3(23.1)$ & $7(12.7)$ & 0.34 \\
\hline $\begin{array}{l}\text { Any oncogenic subtype }(16,18,31,33,35,39,45,51 \text {, } \\
52,56,58,59,68,73,82)\end{array}$ & $1(2.9)$ & $2(5.9)$ & 0.56 & $1(7.7)$ & $2(3.6)$ & 0.52 \\
\hline Any vaccine subtype $(6,11,16,18)$ & $0(0)$ & $1(2.9)$ & 0.32 & $0(0)$ & $1(1.8)$ & 0.62 \\
\hline HPV 16 & $0(0)$ & $1(2.9)$ & 0.32 & $0(0)$ & $1(1.8)$ & 0.62 \\
\hline Multiple subtypes & $2(5.9)$ & $4(11.8)$ & 0.41 & $2(15.4)$ & $4(7.3)$ & 0.35 \\
\hline \multicolumn{7}{|l|}{ GENITAL HPV } \\
\hline Any & $31(91.2)$ & $20(58.8)$ & 0.005 & $13(100.0)$ & $38(69.1)$ & 0.02 \\
\hline $\begin{array}{l}\text { Any oncogenic subtype }(16,18,31,33,35,39,45,51 \text {, } \\
52,56,58,59,68,73,82)\end{array}$ & $25(73.5)$ & $10(29.4)$ & 0.0001 & $10(76.9)$ & $25(45.5)$ & 0.04 \\
\hline Any vaccine subtype $(6,11,16,18)$ & $13(38.2)$ & $6(17.65)$ & 0.02 & $9(69.2)$ & $10(18.2)$ & $<0.0001$ \\
\hline HPV 16 & $7(20.6)$ & $4(11.8)$ & 0.18 & $4(30.8)$ & $7(12.7)$ & 0.11 \\
\hline Multiple subtypes & $20(58.8)$ & 7 (20.6) & 0.0003 & 11 (84.6) & $16(29.1)$ & $<0.0001$ \\
\hline
\end{tabular}

${ }^{*} p$ Values comparing male and female partners were calculated using McNemar's test for the comparison between couples.

* $p$ Values comparing HIV+ and HIV- subjects were calculated using Chi-squared for the comparison between HIV+ and HIV- individuals.

oncogenic HPV prevalence (7.7 vs. $3.6 \%, p=0.52)$ and multiple HPV infections ( 15.4 vs. $7.3 \%, p=0.35$ ) in HIV-infected vs. HIV-uninfected individuals, but this finding was not statistically significant.

\section{CONCORDANT HPV INFECTION}

Concordant type-specific oral-genital HPV infection was detected in $4 / 34(12 \%)$ couples (Figure 1). In $3(75 \%)$ of these four couples the partner with oral HPV reported ever performing oral sex. Among the four couples with concordant oral-genital HPV infection, two couples had concordant HPV 62 infection, one couple had concordant HPV 16 infection, and one couple had multiple concordant subtypes (HPV 33/35/58) (Table 3). There were nine couples where at least one individual had an oral HPV infection, and only one of these couples had concordant oral-oral infection (this couple also had genital-genital and genital-oral concordance with this same HPV type; Table 3). Interestingly, in this couple neither partner reported ever performing oral sex. Among those with oral HPV, men with oral HPV infection (four of six; 67\%) were more likely than women with oral HPV infection (one of four; $25 \%)$ to have a partner with concordant genital HPV infection $(p=0.52)$.

At least one type-specific concordant vaginal-penile HPV infection was observed in 35\% of couples (Figure 1). The proportion with concordant vaginal-penile HPV infection varied by HIV status as HIV-uninfected couples displayed 22\% concordance, HIV-discordant couples displayed 56\% concordance, and HIVconcordant couples displayed $100 \%$ concordant vaginal-penile infection $(p=0.028)$.

\section{RISK FACTORS FOR PREVALENT ORAL HPV INFECTION}

In multivariate analysis, oral HPV prevalence was higher, although not statistically significantly different, among HIV-positive individuals (OR: 5.35; 95\% CI 0.64-44.69), males (OR: 5.06;
95\% CI $0.71-36.21$ ), and those with $\geq 2$ lifetime oral sex partners compared to those with $<2$ lifetime oral sex partners (OR: 4.24; 95\% CI 0.76-23.62), Table 4.

\section{DISCUSSION}

This is one of the first studies to explore oral-genital HPV concordance in couples. We found that $12 \%$ of couples displayed oral-genital concordance and among these couples the majority had male oral HPV infection concordant with female vaginal HPV infection. This is consistent with higher likelihood of vaginal-tooral transmission as compared to penile-to-oral transmission, and may help explain previously reported findings of a lack of significant association between oral-penile contact and incident oral HPV infections amongst women (21). Oral-oral HPV concordance was rare in our study, even among HIV-infected individuals, consistent with no or low salivary transmission.

Our study demonstrated oral HPV prevalence of 15\%, consistent with previous studies from South Africa, which showed an oral HPV prevalence of 20-25\% (22, 23). Risk factors for oral HPV infection were similar to those reported in other studies, including performing oral sex, male gender, and HIV-infection $(4,24)$.

Vaginal HPV was detected in $>90 \%$ of females in our study and the majority of these individuals were found to have oncogenic HPV subtypes. Direct comparisons to previously reported estimates of vaginal HPV amongst women in South Africa are difficult as previous studies report HPV prevalence based on degree of dysplasia present, however population based estimates previously reported for any HPV subtype in women with normal cytology were roughly $21 \%(25,26)$ and ranged from 3.6 to $63 \%$ for high-risk subtypes 16 and 18 depending on degree of dysplasia present (22, 25-29). Additionally, HPV prevalence amongst HIV-positive women in South Africa approaches 80\% (11). Our overall reported vaginal HPV prevalence exceeds these previously reported estimates, although our sample size was small. When 


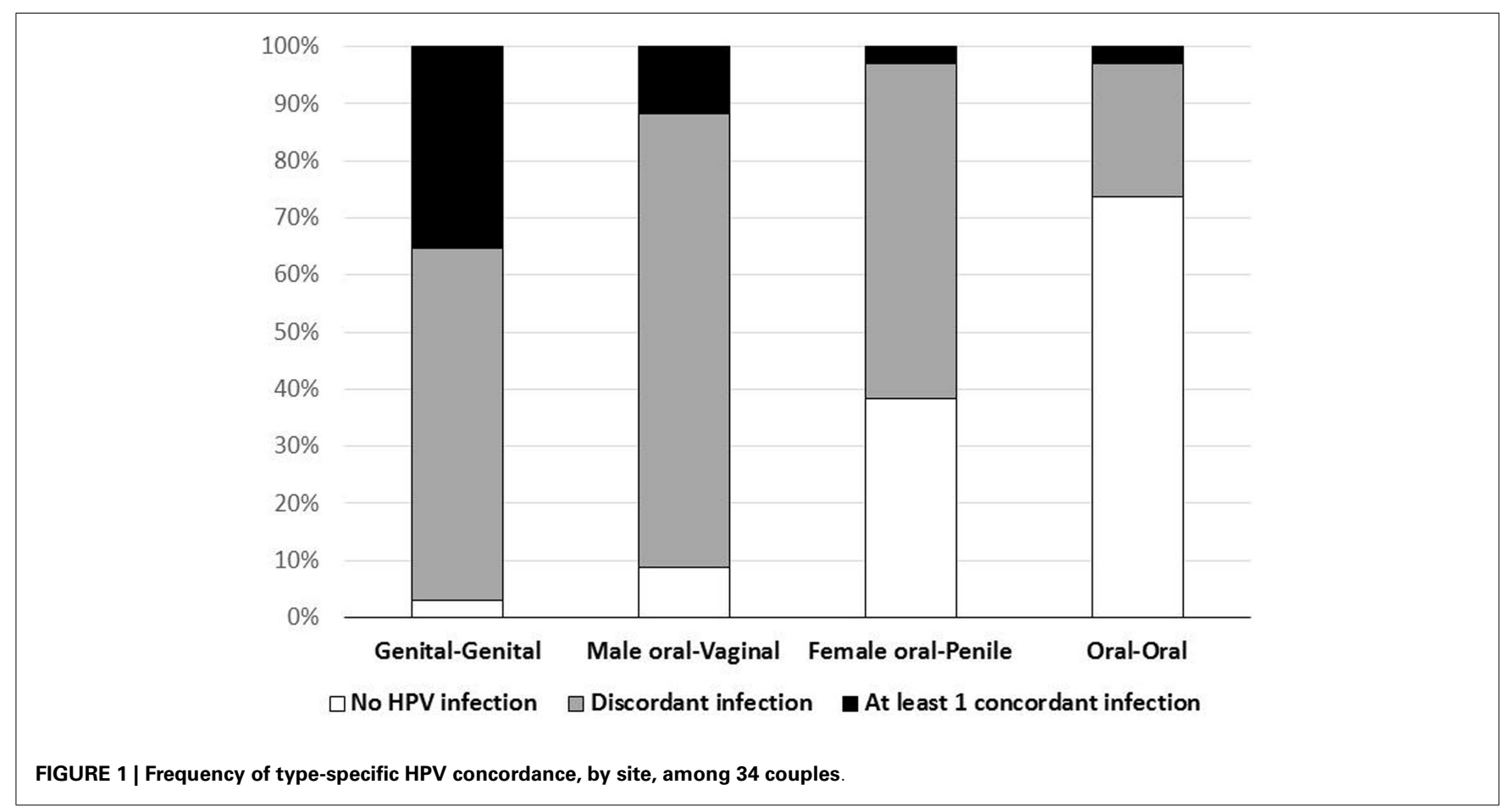

Table 3 | Oral-genital concordance couple characteristics among nine couples with at least one oral HPV infection.

\begin{tabular}{|c|c|c|c|c|c|c|c|c|}
\hline \multirow[t]{2}{*}{ Couple number } & \multicolumn{2}{|c|}{ Oral HPV } & \multicolumn{2}{|l|}{ Genital HPV } & \multicolumn{2}{|c|}{ HIV status } & \multicolumn{2}{|c|}{ Ever oral sex } \\
\hline & Male & Female & Male & Female & Male & Female & Male & Female \\
\hline 2 & $35 / 33 / 58 / 52$ & - & $6 / 35 / 42 / 45$ & $33 / 35 / 58 / 6 / 45$ & HIV-uninfected & HIV-infected & Yes & Yes \\
\hline 3 & 16 & - & $16 / 66$ & $16 / 51 / 66$ & HIV-uninfected & HIV-uninfected & Yes & Yes \\
\hline 4 & $62 / 72$ & - & - & 62 & HIV-uninfected & HIV-uninfected & Yes & Yes \\
\hline 6 & 72 & - & 54 & $16 / 54$ & HIV-uninfected & HIV-uninfected & Yes & Yes \\
\hline 7 & - & $52 / 33 / 35 / 58$ & - & $62 / 72$ & HIV-uninfected & HIV-infected & Yes & Yes \\
\hline 8 & - & 66 & 52 & $66 / 82$ & HIV-uninfected & HIV-uninfected & Yes & Yes \\
\hline 9 & - & $62 / 74$ & 6/11/33/39/45/64/66/67/83/84 & $26 / 45 / 66 / 82 / 83$ & HIV-infected & HIV-infected & Yes & Yes \\
\hline
\end{tabular}

Concordant oral-genital infections shown in red.

looking solely at oncogenic subtypes (i.e., high-risk) or HPV 16 alone, our findings appear similar $(17,18,20)$.

Penile HPV was detected in 59\% of males and $29 \%$ were found to have oncogenic HPV subtypes. The prevalence of high-risk HPV subtypes amongst males in South Africa has been previously reported as $15 \%$ for circumcised males and $22 \%$ for uncircumcised males (30). In our study, we did not categorize men by circumcision status, and our reported prevalence is moderately higher than these previous studies. There was a strong correlation between HIV status and both genital HPV prevalence and genital-genital HPV concordance between couples, which is consistent with previous studies (31). For oral HPV there was a trend toward higher prevalence amongst HIV-positive individuals, but this finding was not statistically significant.
While this study was cross sectional, the agreement in oralgenital HPV infection between couples is consistent with transmission by oral sex. Additionally, in three out of the four couples with concordant oral-genital HPV infection, the partner with oral HPV reported having performed oral sex, a finding consistent with previous reports of an association between oral HPV prevalence and reported oral sex (32). The remaining couple displayed both oral-oral and oral-genital HPV concordance, but reported no oral sex. Possible modes of transmission in this couple could include deep kissing or auto-inoculation, as both of these modes of transmission have previously been suggested, although not clearly demonstrated $(33,34)$. However, oral-oral HPV concordance was low suggesting HPV may not be transmitted by deep kissing, or may be rare. It is noteworthy that oral-genital 
Table 4 | Unadjusted and adjusted odds ratios of oral HPV infection $(n=68)$

\begin{tabular}{lcccc}
\hline & $\begin{array}{l}\text { Unadjusted } \\
\text { OR }\end{array}$ & $\mathbf{9 5 \%} \mathbf{C l}$ & $\begin{array}{l}\text { Adjusted } \\
\text { OR }\end{array}$ & $\mathbf{9 5 \%} \mathbf{~ C l}$ \\
\hline $\begin{array}{l}\text { Age (per 5 years) } \\
\text { HIV STATUS }\end{array}$ & 1.66 & $0.91-3.03$ & 2.24 & $0.94-5.35$ \\
$\begin{array}{l}\text { HIV-uninfected } \\
\text { HIV-infected }\end{array}$ & 1.00 & 1.00 & 1.00 & 1.00 \\
$\begin{array}{l}\text { GENDER } \\
\text { Female }\end{array}$ & 2.06 & $0.45-9.35$ & 5.35 & $0.64-44.69$ \\
$\begin{array}{l}\text { Male } \\
\text { NUMBER OF ORAL SEX PARTNERS }\end{array}$ & & & \\
$\begin{array}{l}\text { <2 Lifetime oral } \\
\text { sex partners }\end{array}$ & 1.00 & 1.00 & 1.00 & 1.00 \\
$\begin{array}{l}\text { Z2 Lifetime oral } \\
\text { sex partners }\end{array}$ & 5.22 & $1.01-26.95$ & 4.00 & $0.71-36.21$ \\
\hline
\end{tabular}

concordance was substantially lower than genital-genital concordance, this could be because oral sex is less frequent than vaginal sex and/or because per-act transmissibility could be different for oral vs. genital sex.

This study had several limitations. The small sample size limited the analysis of risk factors for infection. Because data was collected in categories exact medians could not be recorded. Additionally, our study provides cross-sectional data only so could not demonstrate transmission over time from one partner to another. However this study provides some of the first estimates of oral-oral and oral-genital HPV concordance in couples in Africa.

This research demonstrates high prevalence of genital HPV infection and moderate prevalence of oral HPV infection in a South African population with a modest number of sexual partners. The HPV vaccine has recently been shown to be effective in preventing oral, as well as cervical and anal HPV infection (35), and this data underscores the importance of preventative HPV vaccination in South Africa. The concordant oral-genital HPV infection detected in these couples supports the transmission of HPV infection to the mouth by oral sex. Given higher HPV prevalence, persistence, and HPV-associated cancer risk among HIV-infected individuals (8), the prevalence of oncogenic oral HPV infection in this population is of note. HPV-associated oropharyngeal cancer incidence has increased in the U.S. and some European countries over the past several decades (3). Given the high HIV prevalence in South Africa and other countries in the region, as individuals with HIV live longer due to effective ART, it is not known whether a similar increase in HPV-associated oropharyngeal cancer will be observed in this region.

\section{ACKNOWLEDGMENTS}

The authors thank the staff at Zazi Center at the Perinatal HIV Research Center in Soweto, South Africa who helped with the implementation of this study, especially Thandekile Essien, the HIV testing counselors and the participants of the study.

\section{REFERENCES}

1. Walboomers JM, Jacobs MV, Manos MM, Bosch FX, Kummer JA, Shah KV, et al. Human papillomavirus is a necessary cause of invasive cervical cancer worldwide. J Pathol (1999) 189(1):12-9. doi:10.1002/(SICI)1096-9896(199909)189: $1<12::$ AID-PATH431>3.0.CO;2-F

2. Human papillomaviruses. IARC Monographs on the Evaluation of Carcinogenic Risks to Humans. (Vol. 90). Lyon: International Agency for Research on Cancer (2007).

3. Marur S, D'Souza G, Westra WH, Forastiere AA. HPV-associated head and neck cancer: a virus-related cancer epidemic. Lancet Oncol (2010) 11(8):781-9. doi:10.1016/S1470-2045(10)70017-6

4. Beachler DC, Weber KM, Margolick JB, Strickler HD, Cranston RD, Burk RD, et al. Risk factors for oral HPV infection among a high prevalence population of HIV-positive and at-risk HIV-negative adults. Cancer Epidemiol Biomarkers Prev (2012) 21(1):122-33. doi:10.1158/1055-9965.EPI-11-0734

5. Beachler DC, D'Souza G, Sugar EA, Xiao W, Gillison ML. Natural history of anal vs oral HPV infection in HIV-infected men and women. J Infect Dis (2013) 208(2):330-9. doi:10.1093/infdis/jit170

6. WHO/ICO Information Centre on HPV and Cervical Cancer (HPV Information Centre). Human Papillomavirus and Related Cancers in South Africa. Summary report. (2010) [cited 2013 May 5]. Available from: http://www.hpvcentre.net/ statistics/reports/ZAF.pdf

7. Global Report: UNAIDS Report on the Global AIDS Epidemic 2012. (2012) [cited 2013 May 5]. Available from: http://www.unaids.org/en/media/unaids/ contentassets/documents/epidemiology/2012/gr2012/20121120_UNAIDS_ Global_Report_2012_with_annexes_en.pdf

8. Abraham AG, Stickler HD, Jing Y, Gange SJ, Sterling TR, SIlverberg M, et al. Invasive cervical cancer risk among HIV-infected women: a North American multicohort collaboration prospective study. J Acquir Immune Defic Syndr (2013) 62(4):405-13. doi:10.1097/QAI.0b013e31828177d7

9. Clifford GM, Polesel J, Rickenbach M, Dal Maso L, Keiser O, Kofler A, et al. Cancer risk in the Swiss HIV Cohort Study: associations with immunodeficiency, smoking, and highly active antiretroviral therapy. J Natl Cancer Inst (2005) 97(6):425-32. doi:10.1093/jnci/dji072

10. Mqoqi N, Kellet P, Madhoo J, Sitas F. Cancer in South Africa, 1996-1997. Johannesburg: National Cancer Registry of South Africa, National Health Laboratory Service (2003).

11. Moodley JR, Constant D, Hoffman M, Salimo A, Allan B, Rybicki E, et al. Human papillomavirus prevalence, viral load and pre-cancerous lesions of the cervix in women initiating highly active antiretroviral therapy in South Africa: a crosssectional study. BMC Cancer (2009) 9:275. doi:10.1186/1471-2407-9-275

12. Omar T, Schwartz S, Hanrahan C, Modisenyane T, Tshabangu N, Golub JE, et al. Progression and regression of premalignant cervical lesions in HIVinfected women from Soweto: a prospective cohort. AIDS (2011) 25(1):87-94. doi:10.1097/QAD.0b013e328340fd99

13. Adler DH, Kakinami L, Modisenyane T, Tshabangu N, Mohapi L, De Bruyn G, et al. Increased regression and decreased incidence of human papillomavirusrelated cervical lesions among HIV-infected women on HAART. AIDS (2012) 26(13):1645-52. doi:10.1097/QAD.0b013e32835536a3

14. D'Souza G, Fakhry C, Sugar EA, Seaberg EC, Weber K, Minkoff HL, et al. Sixmonth natural history of oral versus cervical human papillomavirus infection. Int J Cancer (2007) 121(1):143-50. doi:10.1002/ijc.22667

15. Giuliano AR, Lazcano E, Villa LL, Flores R, Salmeron J, Lee JH, et al. Circumcision and sexual behavior: factors independently associated with human papillomavirus detection among men in the HIM study. Int J Cancer (2009) 124(6):1251-7. doi:10.1002/ijc.24097

16. D'Souza G, Sugar E, Ruby W, Gravitt P, Gillison M. Analysis of the effect of DNA purification on detection of human papillomavirus in oral rinse samples by PCR. J Clin Microbiol (2005) 43(11):5526-35. doi:10.1128/JCM.43.11.55265535.2005

17. Gravitt PE, Lacey JV Jr, Brinton LA, Barnes WA, Kornegay JR, Greenberg MD, et al. Evaluation of self-collected cervicovaginal cell samples for human papillomavirus testing by polymerase chain reaction. Cancer Epidemiol Biomarkers Prev (2001) 10(2):95-100.

18. Cogliano V, Baan R, Straif K, Grosse Y, Secretan B, El Ghissassi F. Carcinogenicity of human papillomaviruses. Lancet Oncol (2005) 6(4):204. doi:10.1016/S14702045(05)70086-3 
19. Muñoz N, Bosch FX, de Sanjosé S, Herrero R, Castellsaqué X, Shah KV, et al. Epidemiologic classification of human papillomavirus types associated with cervical cancer. $N$ Engl J Med (2003) 348(6):518-27. doi:10.1056/ NEJMoa021641

20. Schiffman M, Clifford G, Buonaguro FM. Classification of weakly carcinogenic human papillomavirus types: addressing the limits of epidemiology at the borderline. Infect Agent Cancer (2009) 4:8. doi:10.1186/1750-9378-4-8

21. Winer RL, Lee SK, Hughes JP, Adam DE, Kiviat NB, Koutsky LA. Genital human papillomavirus infection: incidence and risk factors in a cohort of female university students. Am J Epidemiol (2003) 157:218-26. doi:10.1093/aje/ kwf180

22. Marais DJ, Passmore JA, Denny L, Sampson C, Allan BR, Williamson AL. Cervical and oral human papillomavirus types in HIV-1 positive and negative women with cervical disease in South Africa. J Med Virol (2008) 80(6):953-9. doi:10.1002/jmv.21166

23. Richter KL, van Rensburg EJ, van Heerden WF, Boy SC. Human papilloma virus types in the oral and cervical mucosa of HIV-positive South African women prior to antiretroviral therapy. J Oral Pathol Med (2008) 37(9):555-9. doi:10.1111/j.1600-0714.2008.00670.x

24. Gillison ML, Broutain T, Pickard RK, Tong ZY, Xiao W, Kahle L, et al. Prevalence of oral HPV infection in the United States, 2009-2010. JAMA (2012) 307(7):693-703. doi:10.1001/jama.2012.101

25. Allan B, Marais DJ, Hoffman M, Shapiro S, Williamson AL. Cervical human papillomavirus (HPV) infection in South African women: implications for HPV screening and vaccine strategies. J Clin Microbiol (2008) 46(2):740-2. doi:10.1128/JCM.01981-07

26. Jones HE, Allan BR, Van de Wijgert JH, Altini L, Taylor SM, de Kock A, et al. Agreement between self- and clinician-collected specimen results for detection and typing of high-risk human papillomavirus in specimens from women in Gugulethu, South Africa. J Clin Microbiol (2007) 45(6):1679-83. doi:10.1128/JCM.02369-06

27. Kay P, Soeters R, Nevin J, Denny L, Dehaeck CM, Williamson AL. High prevalence of HPV 16 in South African women with cancer of the cervix and cervical intraepithelial neoplasia. J Med Virol (2003) 71(2):265-73. doi:10.1002/jmv. 10479

28. Pegoraro RJ, Rom L, Lanning PA, Moodley M, Naiker S, Moodley J. P53 codon 72 polymorphism and human papillomavirus type in relation to cervical cancer in South African women. Int J Gynecol Cancer (2002) 12(4):383-8. doi:10.1046/j.1525-1438.2002.01109.x

29. Williamson AL, Brink NS, Dehaeck CM, Ovens S, Soeters R, Rybicki EP. Typing of human papillomaviruses in cervical carcinoma biopsies from Cape Town. J Med Virol (1994) 43(3):231-7. doi:10.1002/jmv.1890430307
30. Auvert B, Sobngwi-Tambekou J, Cutler E, Nieuwoudt M, Lissouba P, Puren A, et al. Effect of male circumcision on the prevalence of high-risk human papillomavirus in young men: results of a randomized controlled trial conducted in Orange Farm, South Africa. J Infect Dis (2009) 199(1):14-9. doi:10.1086/595566

31. Mbulawa ZZ, Coetzee D, Marais DJ, Kamupira M, Zwane E, Allan B, et al. Genital human papillomavirus prevalence and human papillomavirus concordance in heterosexual couples are positively associated with human immunodeficiency virus coinfection. J Infect Dis (2009) 199(10):1514-24. doi:10.1086/598220

32. Kreimer AR, Alberg AJ, Daniel R, Gravitt PE, Viscidi R, Garrett ES, et al. Oral human papillomavirus infection in adults is associated with sexual behavior and HIV serostatus. J Infect Dis (2004) 189(4):686-98. doi:10.1086/381504

33. Rintala M, Grénman S, Puranen M, Syrjänen S. Natural history of oral papillomavirus infections in spouses: a prospective Finnish HPV Family Study. J Clin Virol (2006) 35(1):89-94. doi:10.1016/j.jcv.2005.05.012

34. Fakhry C, D’Souza G, Sugar E, Weber K, Goshu E, Minkoff H, et al. Relationship between prevalent oral and cervical human papillomavirus infections in human immunodeficiency virus-positive and -negative women. J Clin Microbiol (2006) 44(12):4479-85. doi:10.1128/JCM.01321-06

35. Herrero R, Quint W, Hildesheim A, Gonzalez P, Struijk L, Katki HA, et al. Reduced prevalence of oral human papillomavirus (HPV) 4 years after bivalent HPV vaccination in a randomized clinical trial in Costa Rica. PLoS One (2013) 8(7):e68329. doi:10.1371/journal.pone.0068329

Conflict of Interest Statement: Gypsyamber D'Souza has research support for Merck Inc. The other co-authors declare that the research was conducted in the absence of any commercial or financial relationships that could be construed as a potential conflict of interest.

Received: 01 September 2013; paper pending published: 26 September 2013; accepted: 28 November 2013; published online: 12 December 2013.

Citation: Vogt SL, Gravitt PE, Martinson NA, Hoffmann Jand D'Souza G (2013) Concordant oral-genital HPV infection in South Africa couples: evidence for transmission. Front. Oncol. 3:303. doi: 10.3389/fonc.2013.00303

This article was submitted to Cancer Epidemiology and Prevention, a section of the journal Frontiers in Oncology.

Copyright (c) 2013 Vogt, Gravitt, Martinson, Hoffmann and D'Souza. This is an openaccess article distributed under the terms of the Creative Commons Attribution License (CC BY). The use, distribution or reproduction in other forums is permitted, provided the original author(s) or licensor are credited and that the original publication in this journal is cited, in accordance with accepted academic practice. No use, distribution or reproduction is permitted which does not comply with these terms. 